Henderson, M. E. K. (1957). J. gen. Microbiol. 16, 686-695

\title{
Metabolism of Methoxylated Aromatic Compounds by Soil Fungi
}

\author{
By MOIRA E. K. HENDERSON
}

The Macaulay Institute for Soil Research, Craigiebuckler, Aberdeen

\begin{abstract}
SUMMARY: The metabolism of methoxylated aromatic compounds by the soil fungi Haplographium sp., Hormodendrum sp. and Penicillium sp. has been investigated. A study of rates of decomposition of mono-methoxybenzoic acids by Hormodendrum sp. revealed that they are most rapidly attacked in the order para $(p)$, $m e t a(m)$ and ortho $(o)$. In respiration studies with all three fungi the $p$ form was again found to be metabolized most rapidly. In the initial stage of attack the methoxyl group is replaced by a hydroxyl group. Penicillium sp. also formed $p$-methoxyphenol from $p$-methoxybenzoic acid. A study of the rates of metabolism of monohydroxybenzoic acids revealed that they are attacked in the same order as the monomethoxybenzoic acids. $p$-Hydroxybenzoic acid formed from $p$-methoxybenzoic acid is further metabolized to protocatechuic acid by Hormodendrum sp. and Penicillium sp. When veratric acid (3:4-dimethoxybenzoic acid) is incubated with Hormodendrum sp. and Penicillium sp. the methoxyl group in the $p$ position is replaced by a hydroxyl group to give vanillic acid. All three fungi formed two unidentified phenolic compounds from 2:4-dimethoxybenzoic acid. The possible significance of the results in the decomposition of lignin in soil is discussed.
\end{abstract}

Previous investigations revealed that a number of soil fungi were capable of utilizing simple lignin-related phenolic compounds as sole source of carbon (Henderson \& Farmer, 1955) and some information on the metabolism of these compounds has also been obtained (Henderson, 1956). A feature of the decomposition of lignified material in soil is the significant reduction in methoxyl content (e.g. Sowden \& Atkinson, 1949). In the present work a study has been made of the breakdown by certain soil fungi of simple aromatic compounds containing one or more methoxyl groups.

\section{METIIODS}

Organisms. The following fungi were used: Haplographium sp. from deciduous woodland soil; Hormodendrum sp. no. 1 from sand under Scots Pine in an afforested sand dune; Penicillium sp. no. 13 from moorland soil. These fungi were all used previously (Henderson \& Farmer, 1955; Henderson, 1956).

Cultural conditions. Much of the work was based on an adaptation of Kluyver \& van Zijp's (1951) technique; $250 \mathrm{ml}$. conical flasks containing $100 \mathrm{ml}$. of mineral salts solution $\left(\mathrm{NaNO}_{3}, 1.5 \mathrm{~g}\right.$.; $\mathrm{MgSO}_{4} .7 \mathrm{H}_{2} \mathrm{O}, 0.25 \mathrm{~g}$; $\mathrm{KH}_{2} \mathrm{PO}_{4}, 0.5 \mathrm{~g}$; $\mathrm{KCl}, 0.25 \mathrm{~g}$. dissolved in $500 \mathrm{ml}$. water), to which were added $1 \mathrm{~g}$. glucose and $0.5 \mathrm{~g}$. yeast extract, were inoculated with fungal spores and incubated at $21^{\circ}$ for 7 days, by which time a mat of mycelial growth covered the surface of the medium. The medium was poured off and the mat washed three times with sterile distilled water. Sterile solutions of the acids, brought to $\mathrm{pH} 6.5$ before autoclaving, were then added to the flasks. All 
operations were carried out aseptically. After further incubation periods the solutions were analysed.

Chromatographic analysis. In this instance $0 \cdot 1 \%(\mathrm{w} / \mathrm{v})$ solutions were used beneath the fungal mats. At intervals, usually over a period of about 12 days, a flask was removed from the incubator and the solution was poured off, filtered, acidified and extracted 3 times with $10 \mathrm{ml}$. ether. The ether was removed and the residue dissolved in ethanol and applied to No. 1 Whatman filter-paper. Each solution was spotted 8 times by means of a capillary pipette. The papers were developed by the descending method using $n$-butanol/ammonia (sp.gr. $0 \cdot 880) /$ water $\left(80 / 5 / 15\right.$ vol.) over a period of $16 \mathrm{hr}$. at $21^{\circ}$. Two papers were used for each extract, one being sprayed with diazotized sulphanilic acid (Bray, Thorpe \& White, 1950) for detection of phenols, the other with a buffered spray (Fewster \& Hall, 1951) for detection of acids.

Spectrochemical analysis. For this purpose $0.01 \mathrm{~m}$ solutions were used beneath the fungal mats and $1 \mathrm{ml}$. samples removed aseptically from each flask at intervals of a few days, the frequency of sampling being governed by the rate of disappearance of the compound under investigation. The samples were diluted to $5 \mathrm{ml}$. and the disappearance of the compounds followed by studying their absorption in the ultraviolet region.

Methoxyl determination. The solution (initially $0 \cdot 01 \mathrm{M}$ ) was decanted from the flask and the mat washed 3 times with distilled water. The solution and washings were filtered and evaporated to dryness over a water-bath. The residue was further dried in a vacuum desiccator until of constant weight. The methoxyl determination was then carried out by the method of Vieboch \& Brecher (1930). To determine their methoxyl content the mycelial mats were dried in a vacuum desiccator, powdered and weighed. The powder was returned to the desiccator and left until its weight became constant. Methoxyl determination was then carried out as above.

Respiration studies. The spores were incubated overnight in the presence of mineral salts, buffer and yeast cxtract. These solutions and the conditions and methods were as previously described (Henderson, 1956). Solutions of the substances under investigation were tipped in from the side-arms on the following morning.

\section{RESULTS}

\section{Metabolism of monomethoxybenzoic acids by soil fungi}

Decomposition of monomethoxybenzoic acids. Mycelial mats of Hormodendrum sp. were incubated on $0.01 \mathrm{~m}$ solutions of the three monomethoxybenzoic acids brought to $\mathrm{pH} 6 \cdot 5$. Samples were removed from the flasks at intervals, and the disappearance of the acids was followed by the decrease in absorption in acid solution in which the maxima for $o-, m$ - and $p$-methoxybenzoic acids are at 296,296 and $257 \mathrm{~m} \mu$., respectively. The results showed that $p$-methoxybenzoic acid was much more rapidly attacked than were the $o$ and $m$ compounds. After 14 days the concentration of $p$-methoxybenzoic acid was reduced to $9 \cdot 8 \%$ of the original concentration, while $71.5 \%$ of $m$-methoxybenzoic acid and $89 \%$ of $o$-methoxybenzoic acid remained. 
Respiration studies with monomethoxybenzoic acids. At 0.0083 м concentrations of the acids (Table 1), Haplographium sp. and Hormodendrum sp. showed increased oxygen uptakes which were greatest in the presence of the $p$ form. In the presence of the $o$ and $m$ forms the uptakes by Haplographium sp. were similar, while Hormodendrum sp. gave a marked increase with the $m$

Table 1. Respiration of Haplographium sp., Hormodendrum sp. and Penicillium sp. on monomethoxybenzoic acids

$1 \mathrm{mI}$. spore suspension added to vessels (Haplographium, $8 \times 10^{8}$; Hormodendrum, (a) $4.8 \times 10^{8}$; (b) $4.7 \times 10^{8}$; Penicillium, (a) $8.13 \times 10^{8} ;$ (b) $8.36 \times 10^{8} ;$ (c) $8.66 \times 10^{8}$ spores/ ml.) $+0.5 \mathrm{ml}$. mineral salts solution $+0.5 \mathrm{ml}$. buffer (Haplographium and Hormodendrum Sørensen's phosphate buffer, pH 5.3; Penicillium McIlvaine's citrate + phosphate buffer, pH 3.0) $+0.5 \mathrm{ml}$. yeast extract (Haplographium and Penicillium $0.125 \%$ Hormodendrum $0.48 \%(w / v))$. Centre cup contained $0.2 \mathrm{ml} .5 \%(\mathrm{w} / \mathrm{v}) \mathrm{KOH} ; 0.5 \mathrm{ml}$. substrate acid solution (neutralized) tipped in from side-arms.

$\begin{array}{cccccc}\text { Organism } & \begin{array}{c}\text { vessel } \\ (\mathrm{M})\end{array} & \text { o-Acid } & m \text {-Acid } & p \text {-Acid } & \text { Control } \\ \text { Haplographium } \text { sp. } & 0.0083 & 177 & 169 & 300 & 18 \\ \text { Hormodendrum } \text { sp. }(a) & 0.0083 & 52 & 148 & 213 & 40 \\ (b) & 0.0017 & 42 & 99 & 167 & 41 \\ \text { Penicillium sp. }(\text { a }) & 0.0083 & 140 & 82 & 240 & 252 \\ (b) & 0.0017 & 228 & 169 & 208 & 264 \\ (c) & 0.0010 & 178 & 176 & 189 & 159\end{array}$

Concentration Oxygen uptake over the $5 \mathrm{hr}$. period following of acid in the addition of substrates $(\mu \mathrm{l}$.)

form only. When the concentration of the acids was decreased to $0.0017 \mathrm{M}$ the oxygen uptakes by Hormodendrum sp. in the presence of all three were correspondingly decreased. The small uptake with $o$-methoxybenzoic acid at the higher concentration was therefore indicative of a low ability to attack this acid and was not a result of an inhibitory concentration. The oxygen uptake by Penicillium sp. was markedly inhibited by $o$ - and $m$-methoxybenzoic acids at $0.0083 \mathrm{M}$, while in the presence of $p$-methoxybenzoic acid at the same concentration it was similar to that of the control. When the concentration of the acids was decreased to give a final concentration in the vessels of $0.0017 \mathrm{M}$, the inhibition by the $o$ and $m$ acids was decreased. At $0.001 \mathrm{M}$ the oxygen uptake in the presence of either acid was greater than that of the control.

Conversion of methoxy to hydroxy groups in monomethoxybenzoic acids. An investigation of the products of decomposition of the monomethoxybenzoic acids was made by paper chromatography. Mycelial mats of Haplographium sp., Hormodendrum sp. and Penicillium sp. were incubated on $0 \cdot 1 \%(\mathrm{w} / \mathrm{v})$ solutions of $o-, m$ - and $p$-methoxybenzoic acids. The solutions were extracted and analysed by paper chromatography at intervals of a few days and in each case the corresponding hydroxy-acid was found in the extract. Only faint traces of $o$ - and $p$-hydroxybenzoic acids were formed, but very strong spots of $m$-hydroxybenzoic acid were obtained.

In addition to o-hydroxybenzoic acid, Haplographium sp. and Penicillium sp. produced from $o$-methoxybenzoic acid an unidentified substance which reacted with diazotized sulphanilic acid to give a purple spot of $\boldsymbol{R}_{\boldsymbol{r}} \mathbf{0} \cdot \mathbf{1 3}$. Also, from $p$-methoxybenzoic acid, Penicillium sp. formed $p$-methoxyphenol, 
visible on the papers sprayed with diazotized sulphanilic acid as a lilac spot of $R_{F} 0 \cdot 94$.

Confirmation of the $m$-methoxybenzoic $\rightarrow m$-hydroxybenzoic acid conversion was obtained by spectrochemical analysis. The extract from a culture in which Haplographium sp. had been incubated over $m$-methoxybenzoic acid for 2 days was applied 6 times to each of 5 spots on a chromatography paper. The paper was developed with butanol/ammonia/water, dried, and a strip cut from each side. One strip was sprayed with diazotized sulphanilic acid, the other with buffered indicator spray so that the hydroxy acid and residual methoxy acid could be located. The corresponding portion of the paper containing the hydroxy acid was then cut out and the acid extracted by cutting this portion into smaller strips which were immersed in $5 \mathrm{ml} .0 \cdot 1 \%(\mathrm{w} / \mathrm{v}) \mathrm{NaOH}$ maintained at $50^{\circ}$ for $15 \mathrm{~min}$. This solution of the acid was then cooled and examined by u.v. spectrometry. The extract showed the maxima of $m$-hydroxybenzoic acid at $297 \mathrm{~m} \mu$. (acid solution) and at $312 \mathrm{~m} \mu$. (alkaline).

The formation of $p$-methoxyphenol from $p$-methoxybenzoic acid was also confirmed in a similar manner. The extract, which contained residual $p$ methoxybenzoic acid and $p$-hydroxybenzoic acid in addition to $p$-methoxyphenol, was dissolved in ether and extracted twice with $1 \%(\mathrm{w} / \mathrm{v})$ sodium bicarbonate solution to remove the acids. The ether layer was then washed once with slightly acidified water and once with water. The ether was removed and the residue used for spectrochemical analysis. Its ultraviolet and infrared spectra were the same as those of authentic $p$-methoxyphenol.

The fate of the methoxyl group on conversion of monomethoxy to monohydroxybenzoic acids. This was studied by estimating the methoxyl content of a solution of $p$-methoxybenzoic acid after 6 days of incubation under a mat of Hormodendrum sp. Spectrochemical analysis showed that by this time the concentration of the acid was decreased to $30 \%$ of the original concentration. Therefore a comparison of the total residual methoxyl content with the residual methoxy-acid content would indicate whether the methoxyl group was being transferred to another molecule or whether it was being removed entirely from the solution. Chemical analysis in fact showed that the methoxyl content had been decreased to $31 \cdot 29 \%$ of the original concentration, a figure which corresponds closely with the decrease in concentration of the acid.

It was thought possible that the methoxyl groups were being transferred to the mycelium in some way and accumulating there. In order to examine this possibility two mycelial mats of Hormodendrum sp., treated in a similar manner except that one was incubated over $p$-methoxybenzoic acid and the other over distilled water for 6 days, were washed, dried and powdered. Estimation of the methoxyl contents of the powders revealed that the different mats had the same methoxyl content, $\mathbf{0 . 5 8 6} \%$ for that incubated over the methoxy acid and $0.581 \%$ for that incubated over distilled water. These results indicate that if the methoxyl group were being transferred to another molecule, as seems probable, this molecule did not accumulate but was rapidly decomposed. A further possibility is that a volatile compound was being released. Attempts to trap and identify volatile products were not successful. 
Metabolism of hydroxybenzoic acids formed from methoxybenzoic acids

Decomposition of monohydroxybenzoic acids. To follow the relative rates of disappearance of the hydroxybenzoic acids, mats of Hormodendrum sp. were incubated over $0.01 \mathrm{~m}$ solutions of the three acids brought to $\mathrm{pH} 6.5$ and samples were removed at intervals for spectrochemical analysis. The disappearance of the acids was followed by the decrease in their absorption in alkaline solution in which the maxima for $o-, m$ - and $p$-hydroxybenzoic acid are 296, 311 and $280 \mathrm{~m} \mu$., respectively. The results showed that $m$ - and $p$-hydroxybenzoic acids were quickly metabolized and after 10 days the latter had almost disappeared while the former was decreased to $7 \%$ of the original concentration. Salicylic acid was removed much more slowly, and after 10 days $57 \%$ of the original amount was still present.

Table 2. Respiration of Haplographium sp., Hormodendrum sp. and Penicillium sp. on monohydroxybenzoic acids

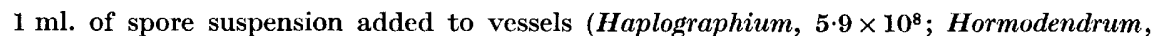
$8.7 \times 10^{8} ;$ Penicillium, $7.96 \times 10^{8}$ spores $/ \mathrm{ml}$. $)+0.5 \mathrm{ml}$. mineral salts solution $+0.5 \mathrm{ml}$. buffer (Haplographium and Hormodendrum Sørensen's phosphate buffer, pH 5.3; Penicillium MeIlvaine's citrate + phosphate buffer, pH 3.0) + 0.5 ml. yeast extract (Haplographium and Penicillium $0.125 \%$; Hormodendrum $0.48 \%(\mathrm{w} / \mathrm{v})$ ). Centre cup contained $0.2 \mathrm{ml} .5 \%$ (w/v) KOH. $0.5 \mathrm{ml}$. substrate acid solution (0.05 M, neutralized) tipped in from side-arms to give a final concentration of $0.0083 \mathrm{~m}$ in vessels.

\begin{tabular}{lcccc}
\multicolumn{1}{c}{ Organism } & $o$-Acid & $m$-Acid & $p$-Acid & Control \\
Haplographium sp. & 115 & 68 & 234 & 30 \\
Hormodendrum sp. & 145 & 101 & 166 & 72 \\
Penicillium sp. & 17 & 329 & 482 & 196
\end{tabular}

Respiration studies with monohydroxybenzoic acids. These acids were all oxidized by the four fungi (Table 2), with the exception of $o$-hydroxybenzoic acid which was inhibitory towards Penicillium sp. at the concentration used. The remaining fungi oxidized $o$-hydroxybenzoic acid more rapidly than they oxidized $m$-hydroxybenzoic acid. Of the three acids, $p$-hydroxybenzoic was oxidized most rapidly by all four fungi.

Further conversion of monohydroxybenzoic acids. It is well established for bacteria that $p$-hydroxybenzoic acid is converted to protocatechuic acid (3:4-dihydroxybenzoic acid) before rupture of the ring, with the subsequent formation of $\beta$-ketoadipic acid (Evans, 1947; Evans, Parr \& Evans, 1949). Walker \& Evans (1952) showed that Pseudomonas fluorescens grown on $m$-hydroxybenzoic acid was simultaneously adapted to gentisic acid (2:5dihydroxybenzoic acid). They did not identify the product of ring cleavage. Evans (1947) found that Vibrio sp. converted $m$-hydroxybenzoic acid to protocatechuic acid. According to Walker \& Evans the pathway of oxidation of salicylic acid by Ps. fuorescens is of a different type and organisms grown on this acid were simultaneously adapted to catechol and to the conversion of 
cis-cis muconic acid to $\beta$-ketoadipic acid. Evans fround that Vibrio sp. had no action on salicylic acid.

Haplographium sp., Hormodendrum sp. and Penicillium sp. were incubated on solutions of the acids, and the solutions were examined by paper chromatography as before. From Hormodendrum sp. and Penicillium sp. cultures on $p$-hydroxybenzoic acid spots with $\boldsymbol{R}_{F}$ corresponding to that of protocatechuic acid were obtained after incubation periods of 2 and 6 days. The spot from the 2-day Hormodendrum sp. culture was extracted from the paper by the method already described for the extraction of $m$-hydroxybenzoic acid. In this instance the solvent used to obtain separation of protocatechuic acid from residual $p$-hydroxybenzoic acid was $n$-propanol/ammonia/water $(80 / 5 / 15 \mathrm{vol}$.). The protocatechuic acid was extracted from the papers with borax phosphate buffer ( $\mathrm{pH} 7$ ) and phosphate buffer ( $\mathrm{pH}$ 6.9). In borax buffer the maxima obtained were at 293 and $253 \mathrm{~m} \mu$. (Swain, 1954) and in phosphate buffer at $250 \mathrm{~m} \mu$. These are identical with the maxima of authentic protocatechuic acid. There was no trace of protocatechuic acid in Haplographium sp. cultures.

\section{Metabolism of di- and tri-methoxybenzoic acids}

Respiration studies. These were carried out with 2:4- and 3:4-dimethoxybenzoic acids and 3:4:5-trimethoxybenzoic acid (Table 3). Only Haplographium sp. and Hormodendrum sp. showed any increase in oxygen consumption. These increases were small compared with those obtained in the presence of the mono-

Table 3. Respiration of Haplographium sp., Hormodendrum $s p$. and Penicillium sp. on di-and tri-methoxybenzoic acids

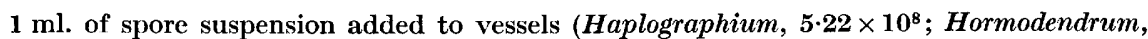
$4.03 \times 10^{8} ;$ Penicillium, (a) $6.0 \times 10^{8} ;$ (b) $6.86 \times 10^{8}$ spores $/ \mathrm{ml}$. $)+0.5 \mathrm{ml}$. mineral salts solution $+0.5 \mathrm{ml}$. buffer (Haplographium and Hormodendrum Sørensen's phosphate buffer, pH 5·3; Penicillium McIlvaine's citrate + phosphate buffer, pH 3.0) $+0 \cdot 5 \mathrm{ml}$. yeast extract (Haplographium and Penicillium 0.125\%; Hormodendrum 0.48\% (w/v)). Centre cup contained $0.2 \mathrm{ml} .5 \%(\mathrm{w} / \mathrm{v})$ KOH; $0.5 \mathrm{ml}$. substrate acid solution (neutralized) tipped in from side-arms.

\begin{tabular}{|c|c|c|c|c|c|}
\hline \multirow[b]{2}{*}{ Organism } & \multirow{2}{*}{$\begin{array}{l}\text { Concentration } \\
\text { of substrate } \\
\text { acid in } \\
\text { vessels } \\
\text { (M) }\end{array}$} & \multicolumn{4}{|c|}{$\begin{array}{c}\text { Oxygen uptake over the } 5 \mathrm{hr} \text {. period following } \\
\text { the addition of substrates }(\mu \mathrm{l} .)\end{array}$} \\
\hline & & $\begin{array}{c}2: 4- \\
\text { Dimethoxy }\end{array}$ & $\begin{array}{c}\text { 3:4- } \\
\text { Dimethoxy }\end{array}$ & $\begin{array}{c}\text { 3:4:5- } \\
\text { Trimethoxy }\end{array}$ & Control \\
\hline Haplographium sp. & $0 \cdot 0083$ & 109 & 94 & 88 & 83 \\
\hline Hormodendrum sp. & $0 \cdot 0083$ & 62 & 59 & 42 & 36 \\
\hline Penicillium sp. $(a)$ & $0 \cdot 0083$ & 119 & 91 & 97 & 170 \\
\hline (b) & 0.0017 & 297 & 290 & 330 & 298 \\
\hline
\end{tabular}

methoxybenzoic acids. 'Thus Haplographium sp., which gave marked increases with the $o$-, $m$ - and $p$-methoxybenzoic acids, gave a small increased uptake only with 2:4-dimethoxybenzoic acid. Similarly, Hormodendrum sp., which showed marked increases with $m$ - and $p$-methoxybenzoic acids, gave only small increases with the dimethoxybenzoic acids. Penicillium sp. was inhibited by all the acids at $0.0083 \mathrm{M}$, but the inhibition was not obtained when the 
concentration of the acids was reduced to $0.0017 \mathrm{M}$ (cf. monomethoxybenzoic acids).

Decomposition of veratric acid. The metabolism of veratric acid (3:4-dimethoxybenzoic acid) by Penicillium sp. was followed further by absorption spectrometry. A mat of the fungus was incubated on a $0.01 \mathrm{~m}$ solution of the acid brought to $\mathrm{pH} 6 \cdot 5$. Paper chromatography indicated that vanillic acid was formed from veratric acid by Penicillium sp. (see later) and confirmation of this was obtained by absorption spectrometry. The disappearance of the dimethoxy acid was followed by the decrease in absorption at its maximum at $252 \mathrm{~m} \mu$. in alkaline solution, while the formation of vanillic acid was traced by the increase in absorption at its maximum at $300 \mathrm{~m} \mu$. in alkaline solution. The concentration of veratric acid fell to $79 \%$ of the original concentration after one day and thereafter it fell slowly to $39.5 \%$ of the original after 21 days. Vanillic acid reached its maximum concentration $\left(1.1 \times 10^{-4} \mathrm{M}\right)$ after 1 day, and thereafter its concentration fell very slowly and was decreased to half of the above concentration after 21 days. Previously evidence was obtained (Henderson, 1956) that vanillic acid was oxidized by an adaptive enzyme, which may explain the initial accumulation of the acid when formed from veratric acid followed by a gradual diminution in concentration after the formation of the necessary enzyme.

Conversion of methoxy to hydroxy groups in di- and tri-methoxybenzoic acids. Conversion of the methoxy group in the $p$ position of veratric acid (3:4dimethoxybenzoic acid) took place in the presence of Penicillium sp., a strong spot of vanillic acid (3-methoxy-4-hydroxybenzoic acid) being visible on the paper chromatogram after 3 days. Traces of vanillic acid were also present in Hormodendrum sp. cultures but none could be identified in Haplographium sp. cultures.

The three fungi Haplographium sp., Hormodendrum sp. and Penicillium sp. each formed from 2:4-dimethoxybenzoic acid a substance which gave an orange-brown spot of $\boldsymbol{R}_{F} \mathbf{0 . 3 8}$ with diazotized sulphanilic acid. In addition, an orange spot of $\boldsymbol{R}_{F} \mathbf{0 . 1 3}$ was obtained particularly with Penicillium sp. It was not found possible to identify these products by the techniques available.

Conclusive results could not be obtained with 3:4:5-trimethoxybenzoic acid. It was expected that conversion of the methoxy group in the $p$ position (as with 3:4-dimethoxybenzoic acid) would give rise to syringic acid. Faint traces of this acid $\left(\mathbf{R}_{F} \mathbf{0} \cdot 06\right)$ were identified from Haplographium sp. and Penicillium sp. cultures. In addition, a faint orange spot of $\boldsymbol{R}_{F} \mathbf{0 . 1 2}$ was present in cultures of all four fungi; this compound was not identified.

\section{Metabolism of dihydroxybenzoic acids}

A series of respiration experiments was carried out with the six dihydroxybenzoic acids. All three fungi gave small increases in oxygen consumption in the presence of most of the acids. It was, however, not possible to place the acids in any order according to the rates at which they were oxidized. 


\section{DISCUSSION}

In this study of the de-methoxylation of aromatic compounds by fungi the following conversions have been shown to take place:
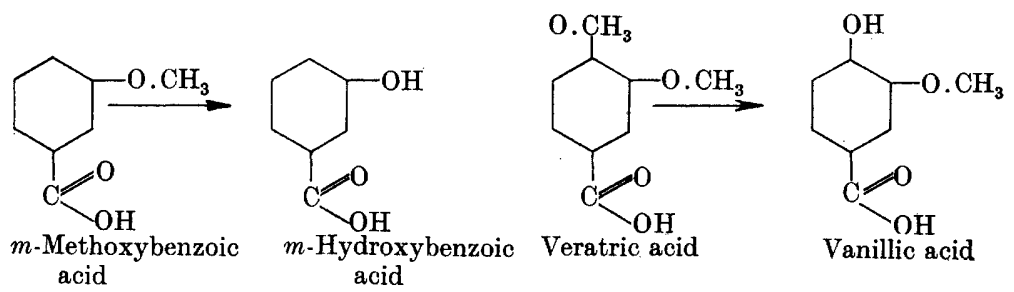

In addition evidence has been obtained by paper chromatography that $o$ - and $p$-methoxybenzoic acids are also converted to the corresponding hydroxybenzoic acids. It is possible that de-methoxylation takes place by a . transference of the methyl group. Little is known concerning such a process in fungi although a number have been shown to form trimethylarsine from arsenic compounds (Challenger, 1945). Transmethylation systems exist in animal tissues, and methyl groups can be transferred from compounds such as choline and betaine (Challenger, 1945). In the present work analysis of the solution and mycelial mat showed that the total methoxyl content of the solution was being decreased, and that there was no accumulation of methoxyl groups in the mycelial mat. Therefore, if transmethylation were occurring the product formed must have been rapidly metabolized or a volatile compound may have been produced, but attempts to trap any such products were not successful.

The formation of protocatechuic acid from $p$-hydroxybenzoic acid has not been demonstrated before for fungi. However, this step is well established in the metabolism of $p$-hydroxybenzoic acid by bacteria and the present work indicates that the fungi used here metabolize this acid by a similar pathway. It has not yet been possible to identify the products formed on rupture of the benzene ring.

Also of interest is the fact that a methoxybenzoic acid is most rapidly attacked when the methoxyl group occupies the position para to the carboxyl group. This was shown by spectrochemical analyses and by respiration studies. Experiments with the hydroxybenzoic acids also showed that the $p$ acid was most rapidly metabolized. Furthermore, the conversion of veratric acid to vanillic acid revealed that a methoxyl group in the $p$ position is preferentially attacked. These results may be compared with those of Gundersen \& Jensen (1956) who, in a study of the decomposition of nitro-phenols, came to the conclusion that $p$-orientation of the groups is important.

Penicillium sp. differed from the other fungi in forming $p$-methoxyphenol from $p$-methoxybenzoic acid, in addition to $p$-hydroxybenzoic acid. There was no evidence of a similar conversion of the other methoxybenzoic acids by this fungus. This reaction is similar to that obtained by Sloane, Crane \& Mayer 
(1951) when they incubated Mycobacterium smegmatis on $p$-aminobenzoic acid and obtained $p$-aminophenol. In this instance the intermediate was aniline.

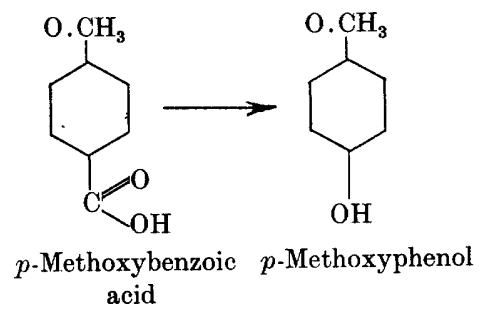

The ability of the present soil fungi to demethylate compounds in which the methoxyl group is attached to the benzene ring may be an important factor in the transformation of lignified plant materials taking place in soil. One feature of this transformation is the reduction of the methoxyl content which Breger (1951) attributes (for peat) to biochemical removal of the methyl groups from lignin with the production of methane and phenolic hydroxyl groups.

I wish to express my thanks to Dr D. M. Webley for his continued interest and advice. I am very grateful to Dr V. C. Farmer for carrying out the spectrochemical analyses and I also wish to thank Dr R. I. Morrison for the methoxyl determinations and Miss D. Brebner for technical assistance.

\section{REFERENCES}

Bray, H. G., Thorpe, W. V. \& White, K. (1950). The fate of certain organic acids and amides in the rabbit. 10. The application of paper chromatography to metabolic studies of hydroxybenzoic acids and amides. Biochem. J. 46, 271.

Breger, I. A. (1951). Chemical and structural relationships of lignin to humic substances. Fuel, 30, 204.

Challenger, F. (1945). Biological methylation. Chem. Rev. 36, 315.

Evans, W. C. (1947). Oxidation of phenol and benzoic acid by some soil bacteria. Biochem. J. 41, 373.

Evans, R. A., Parr, W. H. \& Evans, W. C. (1949). The bacterial oxidation of aromatic compounds. Biochem. .J. 44, viii.

Fewster, M. E. \& Hall, D. A. (1951). Application of buffered solvent systems to the detection of aromatic acids by paper partition chromatography. Nature, Lond. 168, 78.

Gundersen, K. \& Junsen, H. L. (1956). A soil bacterium decomposing organic nitro-compounds. Acta agric. scand. 6, 100.

Henderson, M. E. K. (1956). A study of the metabolism of phenolic compounds by soil fungi using spore suspensions. J. gen. Microbiol. 14, 684 .

Henderson, M. E. K. \& Farmer, V. C. (1955). Utilization by soil fungi of $p$ hydroxybenzaldehyde, ferulic acid, syringaldehyde and vanillin. $J$, gen. Microbiol. 12, 37.

Kluvver, A. J. \& vax ZiJP, J. C. M. (1951). The production of homogentisic acid out of phenylacetic acid by Aspergillus niger. Leeurwenhoek ned. Tijdschr. 17, 47.

Sloane, N. H., Crane, C. \& Mayer, R. L. (1951). Studies on the metabolism of $p$-aminobenzoic acid by Mycobacterium smegmatis. J. biol. Chem. 193, 453. 
Sowden, F. J. \& Atkinson, H. J. (1949). Composition of certain soil organic matter fractions. Soil. Sci. 68, 433.

SwaIn, T. (1954). Spectral studies on phenolic compounds. Chem. \& Ind. (Rev.), p. 1480.

Vieboch, F. \& Brecher, C. (1930). Eine neue Methode zur massanalytischen Bestimmung der Methoxyl- und Äthoxylgruppe, II. Mikro-Analyse. Ber. dtsch. chem. Ges. 63, 3207.

Walker, N. \& Evans, W. C. (1952). Pathways in the metabolism of the monohydroxybenzoic acids by soil bacteria. Biochem. J. 52, xxiii.

(Received 27 December 1956) 